\title{
EAP Textbooks in Iranian Universities: The Subject of Pragmatic-Critical Spotlight
}

\author{
Hamideh Baggali B. (Corresponding author) \\ English Language Department, Azarbaijan Shahid Madani University, Tabriz, Iran \\ E-mail: Baggali_h@yahoo.com \\ Davud Kuhi \\ English Language Department, Maragheh Branch, Islamic Azad University, Maragheh, Iran \\ E-mail: davudkuhi@yahoo.com
}

Received: 23-07-2014

doi:10.7575/aiac.ijalel.v.4n.2p.26
Accepted: 20-09-2014

Published: 01-03-2015

URL: http://dx.doi.org/10.7575/aiac.ijalel.v.4n.2p.26

\begin{abstract}
Increasingly indispensible inquiry for international academic communication has appointed English for Academic Purposes (EAP) as one of the prime focuses of university curriculum designers. The structure of EAP textbooks and numerous need analysis studies have approved reading comprehension as the students' predominant English need in Iranian universities; however, little collective critical research has appraised the implementation of reading pedagogy in EAP textbooks. As a response, the present study investigated the materialization of reading instruction via reading activities in 30 EAP textbooks published in Iran premised on Johns and Davies' (1983) transition of Text As a Linguistic Object (TALO) to Text As a Vehicle of Information (TAVI) in EAP reading in tandem with Jeremy Harmer's (2007) Reading Principles as its valorized analytical points of departure. Furthermore, this study advocated weak antitextbook approach that supports the functionality of textbooks provided that they pedagogically and methodologically appropriate for a target context. As a caution, the results revealed 3 fundamental Principles were not invoked at all and the other 3 were partially considered in design of the activities with grave inefficiencies, which culminated in a dissatisfactory realization of TAVI and incapability in realizing pragmatic objectives of EAP university courses. This revelation demonstrates a cardinal demand for revising EAP textbooks in Iran incorporating a critical stance for enlightening the path of curriculum designers and practitioners.
\end{abstract}

Keywords: EAP textbooks, EAP reading, TAVI, Reading Principles

\section{Introduction}

As English language has been enhancing its domains of application in various areas of science, technology and human communication, English for Academic Purposes (EAP) has been increasingly required to fulfill the applicants' specific academic needs. Clarifying EAP domains of reference Hyland (2006) writes, "EAP attempts to offer systematic, locally managed, solution-oriented approaches that address the pervasive and endemic challenges posed by academic study to a diverse student body by focusing on student needs and discipline-specific communication skills" (p.4). To establish a comprehensive evolutionary depict of EAP, let us take a survey from its flourishing pathway English for Specific Purpose (ESP) to a firm launch of EAP.

\subsection{From ESP to EAP}

Reasonably enough, the advent of each educational branch originates from the academic and social movements of a specific epoch; accordingly, three main trends significant in the emergence and development of English for Specific Purposes (ESP) in the late 1960s include unprecedented development of science and technology in the post-war era after the Second World War demanding an international common language, new approaches in linguistics shifting from language usage to language use in context, and learner-centered education considering learners' needs, attitudes, and interest, according to Hutchinson and Waters (1987). Since then an MA in ESP offered by different universities, ESP courses for international students and well-established international ESP journals have demonstrated ESP as an active area in ELT (Anthony, 1997).

Conceptualization of ESP, then rather inseparable from EAP, slightly varies for different pioneers of the field. Hutchinson and Waters (1987) define ESP as "an approach to language teaching in which all decisions as to content and method are based on the learners' reason for learning" (p.19). Elaborating on ESP attributes as cited in Dudley-Evans and St John (1998), Stevens (1988) makes a distinction between absolute and variable characteristics, defining ESP as a kind of language teaching incorporating the following features,

The absolute characteristics are that ESP consists of English language teaching which is

- designed to meet specific needs of the learner;

- related in content (that is in its themes and topics) to particular disciplines, occupations and activities; 
- centered on the language appropriate to those activities in syntax, lexis, discourse, semantics, etc., and

analysis of this discourse;

- in contrast with 'General English'.

The variable characteristics are that ESP

- may be restricted as to the language skills to be learned (for example reading only);

- may not be taught according to any pre-ordained methodology. (p.3)

Accordingly, absolute characteristics expound ESP as an orientation of language teaching in which the prime focus stands on learners' needs based on discipline-specific resources in contrast to general English. On the other hand, variable characteristics refer to tentative aspects of ESP design like the covered skills and methodology. Not long after, Robinson (1991) states the areas where ESP programs benefit from to serve their function and writes, "ESP is a major activity around the world today. It is an enterprise involving education, training and practice, and drawing upon three major realms of knowledge: language, pedagogy, and the students'/ participants' specialist areas of interest" (p.1).

Moreover, nearly a decade after Stevens's pioneering definition, Dudley-Evans and St John (1998) in their book modified the components of absolute and variable characteristics. The revised version differed from the original one in removing contradictions of ESP with EGP and incorporating a few more variables, in which absolute characteristics refer to the discipline-based specialty of ESP courses in meeting learners' needs both methodologically and linguistically, and variable characteristics imply possible variations in aim, methodology and learners.

Amid constant flourishing of ESP, EAP has initially established itself as one of ESP prime branches, and nowadays it is a distinguished area of English language research and education worldwide (Hyland, 2006). It was originally generated from a pragmatic view to language teaching in order to equip university students and researchers with their fieldspecific English needs. Therefore, 'need analysis' has been a rudimentary and essential step for preparing a purposebased EAP curriculum with a great emphasis on its context-sensitivity. The identified context-specific EAP English needs have been fulfilled by varying methods inspired by the evolving approaches in English language teaching, which has engendered, according to Hyland (2006), four main orientations of lexico-grammar, micro-macro skill, discourse and genre, and critical literacy.

In this study, our analysis will evidently demonstrate that how EAP university textbooks in Iran have been stuck in the first phase, i.e. lexico-grammatical orientation, for over 30 years since their first inception, and how ignorant material designers have been about the critical evaluation and consequent revisions of the textbooks. Accordingly, in the current investigation the analytical approach is entitled 'pragmatic-critical' in a way that when numerous need analysis investigations have ascertained the students' need of micro-macro skill instruction particularly in the area of English reading, the textbooks' pragmatic function should have tended to fulfill the stakeholders' frequently cited needs. To this end, the approach of one shot for every epoch cannot meet the context-sensitive demands of evolving academic fields, and critical appraisal of the EAP materials based on representative theoretical orientations is a necessity for conducting defensible EAP programs.

Although in literature on textbook design there are two opposing poles, namely anti-textbook scholars and pro-textbook producers, this study will adopt an in-between approach that is called "weak anti-textbook" by Harwood (2005). Harwood writes, in this approach, "Textbooks may make life easier for the teacher if the material is locally appropriate and pedagogically sound" (p. 154). In a similar manner, we are anti-oriented whenever the dominant inspiration of a textbook design is intuition and marketability, and a pro-textbook when the foundation lies on a comprehensive research and successive revisions according to the situational requirements and upcoming modified methodologies, approaches and scholarly discussions. This approach not only sounds more logical than the other two extremes, but also, contextually sensitive, EAP teachers in Iranian universities are in need of research-led textbooks since they are either content teachers with no awareness on English teaching approaches and methodologies, or language teachers too amateur in a subject specific discourse. Hence, this study advocates the facilitating role of EAP textbooks provided that they are the subject of constant critical consideration and adaptation.

Aligned with the global atmosphere of EAP trend, it has attracted the attention of academic communities and applied linguists in Iran, which is the matter of elaboration in the section ahead. In addition, it may not be pointless to state that most of Iranian EAP researchers use ESP and EAP interchangeably, and in the following section, the researchers' adopted terms will be cited while they all refer to EAP at universities.

\subsection{EAP in Iran}

Chronologically looking, EAP instruction in Iran has gone through three phases. During the first period, EAP courses were jointly implemented by Iranian Universities and foreign academic centers. The second phase in the 1980s led to the compilation of a number of EAP textbooks. The last stage is characterized by an emphasis on content specificity of EAP textbooks for highly narrow academic disciplines (Atai, 2002). In the second and third phases, inspired by a zeal for optimizing academic performance after Islamic Revolution of Iran, SAMT publications handed by collaboration of English language professors nation-wide took the initiative of devising subject-specific EAP textbooks, and since then numerous EAP textbooks have been published with titles like English for the Students of Physics, English for the Students of Literature, English for the Students of Law, etc. 
While this EAP movement was a valuable purpose-based pragmatic enterprise those days, a strong criticism against their productions is rightly applied to the lack of ongoing critical analysis of EAP textbooks based on students' needs and ELT-EAP reputed advances. It is widely believed by EAP eminent scholars that EAP is a highly situation-sensitive academic field, and the stakeholders cannot be confident about their performance without successive critical evaluations. In the texture of published EAP textbooks in Iran few may care that the myth of considering language as a system in which addition of its components like vocabulary or syntactic elements could once lead to a whole language ability has been long before criticized by functional and communicative language teaching advocates. It is highly acknowledged that designing EAP books in Iran was realized by a functional and pragmatic motive, but materialization of its function through reading activities dates back to the old days of discrete point teaching and grammar translation method, which cannot satisfy the requirements of EAP today.

This inefficiency has been discretely reported by various studies in the domains of need analysis and textbook review. To name a few, Mazdayasna and Tahririan (2008) illuminated the importance of need analysis in ESP courses with particular focus on nursery students. Moslemi, Moinzadeh and Dabaghi (2011), focusing on MA students' ESP needs, revealed an urgent need for revision of ESP policies to meet students' academic requirements. In addition, Karimkhanlouei (2012) analyzed ESP status of medical students, which entailed the necessity of modifying current programs in accordance with their needs. Zangani (2009) studied the effectiveness of ESP textbooks in Iran based on ESP instructors and university students' evaluation and concluded the necessity of their modification according to both new approaches in ELT and students' needs. The research of Amirian and Tavakoli (2009) on the efficiency of ESP courses for engineering students in Iran indicated that while ESP textbooks provided preliminary background for the students, their in-service needs required different ESP training from the one present in the available textbooks. Through investigating the needs of engineering students, Salehi (2010) suggested the improvement of ESP textbooks with incorporation of speaking and writing tasks and less emphasis on translation. Davari, Iranmehr and Erfani (2013) evaluated Iranian ESP textbooks published by Payam Nour University (PNU) shedding light on their drawbacks.

The above articles attempted to call the existing needs of EAP students into consciousness. Regarding the status of English language as a foreign language in the context of Iran, academic communities may generally need English for three main objectives, namely reading skills to deal with comprehending English sources, articles and websites, writing skills to pen articles and books, or speaking and listening skills to perform and participate in international academic gatherings. On closer inspection, however, reading skill has turned to have priority over the others through the history of university EAP instruction in Iran, whose reason can be reasonably sought in preliminary receptive stage of any educational trend to communicate with the available literature, more specifically reading English sources for the students of various academic fields in Iran. Especially, when the students are sophomores or juniors at the time of taking EAP courses, they will predominantly need to read English sources in their field of study to take the initial EAP steps rather than writing or speaking. The widespread significance of English reading skill throughout Iran's EAP history is a reality that in widely evident in the design of available materials and further need analysis investigations (e.g. Khalili \& Daneshvar, 2010; Pouya, 2012; Atefi \& Moradian, 2013; Vosoughi, Davoudi \& Raftari, 2013). Consequently, although English reading may not be an exclusive need of Iran's university students, undoubtedly it comprises one of the predominant components of EAP teaching and textbooks.

\subsection{Research Focus}

One would wonder that an abundant academic, financial and productive investment has been directed towards EAP English reading instruction in Iran; however, little research has been conducted on the realization of effective EAP reading, particularly in the area of critical analysis of EAP textbooks' activities based on the ongoing advances and studies in English language teaching. Consequently, the present research aims to appraise the reading activities of the passages in EAP textbooks in Iran because, as elaborated above, reading skill has been the major English competency component required in academic contexts. Therefore, this research is to address whether reading exercises of EAP textbooks in Iran reflect the prominent reading instruction advances based on the components of TAVI and the concerns of Harmer's (2007) Reading Principles discussed in Methodology. To this end the research questions are as followings,

1. How efficiently has TAVI been materialized in EAP textbooks published in Iran?

2. How efficiently have Reading Principles been invoked in EAP reading activities?

3. How can TAVI and Reading Principles optimize the EAP reading scenario in Iran?

\section{Methodology}

\subsection{Corpus}

The corpus of the current research was comprised of 30 EAP textbooks (listed in Appendix) each for the students of one specific academic field, namely chemistry, accounting, literature, physics, etc., most of which are published by The Organization for Researching and Composing University Textbooks in the Humanities (SAMT) and a handful by other publishing companies in Iran. SAMT is the main responsible company for publishing EAP textbooks in Iran, whose publications are widely available. Since our sampling method was random, the other minor companies were not excluded as well. Thus, the analyzed EAP textbooks were randomly opted from textbook resources obtainable for both EAP practitioners and students, and the pivotal focus was on the organizational and stylistic design of the activities encompassing reading passages whose aim was to provide the students with instruction and competency of reading 
comprehension in English. The given exercises were critically evaluated based on the advocated tasks in TAVI and Harmer's (2007) Reading Principles explained in the following part.

\subsection{Analysis Approach}

Every educational domain and the related subcomponents follow their life in an evolving process; in this regard EAP and effective reading in EAP as the focus of this research are not exceptions. In the following part, transformation of Text As a Linguistic Object (TALO) to Text As a Vehicle of Information (TAVI) in EAP and its organized manifestation in Jeremy Harmer's Reading Principles were explored, and the elaborated underlying similarities and representativeness made the analytical approach of our research to examine the effectiveness of reading activities of EAP textbooks in Iran.

\subsubsection{TALO to TAVI.}

The advocacy of communicative language teaching and content-focused approaches in the evolutionary history of English language teaching did not lose the sight of EAP as one of the important branches of ELT. In line with the current progressive spirit, according to Johns and Davis (1983), one of the most significant modifications of EAP reading was a transition from Text As a Linguistic Object (TALO) to Text As a Vehicle of Information (TAVI). In this approach the pace and accuracy of text information extraction was more important than linguistic concerns; and in accordance with its underlying belief, the practice of TAVI has been improvingly different from that of TALO.

The differentiating elements of TALO from TAVI lie in the five following categories according to Johns and Davis (1983),

1. Selection of texts: The criteria of text selection in TALO are general interest and syntactic-lexical representativeness, which logically culminates in modified and short texts while conceptual domain and students' needs are basic measures of text nomination in TAVI, which puts vocabulary and structure into a secondary importance.

2. Preparatory activities before reading: Lack of providing any preparatory activity except translation of some unfamiliar words is introduced as one of critical drawbacks of TALO method whereas TAVI demands a welldevised pre-reading phase for preliminary directing of purpose establishment and motivation activation.

3. The focus of reading activities: Dealing with a reading text, a TALO teacher slowly surveys throughout the text and asks students some questions about the present structure and vocabulary with a deep focus on what is unknown; conversely, in TAVI the instructor leads students' attention towards what is known and overall meaning of the text without unsystematic interference of lexical-syntactic questions as the matter of importance at the end of reading session.

4. The type of teacher-learner interaction: The teaching-learning sequence in TALO is a reversal of TAVI; teacher monologue and passive students are replaced with group working and active collaborating peers headed by a director called teacher. This type of education helps learners to develop their independency and sets a model for individual learning.

5. Follow-up reading activities: Follow-up reading activities are familiar reading exercises which are designed in TALO in the form of after-reading comprehension questions and lexical or grammatical questions. They write this function is satisfied in TAVI by 4 overall representations, namely information transfer, explanation, extension, and technique application.

\subsubsection{Harmer's Reading Principles}

TAVI's concerns have survived the test of time and essentially been presented in an aligned representation by Harmer (2007). He proposes 6 Principles for English reading skill, whose organized approach can be a suitable touchstone for effective EAP reading due to the underlying similarities between the above mentioned EAP reading modifications and his Principles. Harmer (2007, pp.101-102) outlines Reading Principles as following,

Principle 1: Encourage students to read as often and as much as possible.

Principle 2: Students need to be engaged with what they are reading.

Principle 3: Encourage students to respond to the content of a text (and explore their feeling about it), not just concentrate on its construction.

Principle 4: Prediction is a major factor in reading.

Principle 5: Match the task to the topic when using intensive reading texts.

Principle 6: Good teachers exploit reading texts to the full.

The coalescence of these 6 Principles with the 5 categories of TAVI in materializing an optimized reading instruction is the subject of descriptive articulation in the following section.

\subsubsection{TAVI and Reading Principles in Collaboration}

Principle 1 entails encouraging students to read as extensive as they can along with teachers' intensive instructions. Extensive reading is further reading activity, usually done out of classroom and for pleasure, which is evaluated comprehensible input with low anxiety by Krashen (2003) while intensive reading refers to a detailed concentration on the content and construction of a reading text selected by teachers, which is "accompanied by study activities" (Harmer, 2007, p.100). Focused instruction by intensive reading and preparation for further extensive reading stated in Principle 1 
bear the underlying concern of TAVI in the fourth part, 'the type of teacher-learner interaction' to make an EAP reading process a model for self-study. Subsequently, an effective intensive EAP reading can help students with identifying characteristics of a successful task of reading in accordance with their needs, setting a model for self-study, and encouraging extensive reading motivated by the sense of achievement throughout an independent intensive reading individually or by peers.

Principle 2 respects the idea of considering students as active members of learning and engaging them with the topic of a reading text and its activities to a rich extent, as Davies (1995) precedingly believes a good reading task helps students to interact with a reading text by preparatory activities and conceptual overall engagement with the text stated in parts 2 and 3, and stakeholders' collaboration by active teacher-learner interaction in part 4 . The present Principle forms an alliance with the zeal of TAVI for learner and learning centered approach and students' group work. It differs from teacher monologue, teacher-centered instruction and evaluation in TALO and further locates students in the center of an educational process advocating maximum engagement of students in resemblance to Principle 2.

Regarding Principle 3, Harmer (2007) writes, "Of course, it is important for students to study reading texts in class in order to find out such things as the way they use language, the number of paragraphs...It is especially important that they should be allowed to show their feelings about the topic" (p.101). Accordingly, a successful reading activity demands students' affective engagement. "The affective domain is the emotional side of human behavior, and it may be juxtaposed to the cognitive side" (Brown, 2007, p.153). The same issue has been raised in the elaboration of TAVI to awaken students' interest in EAP reading as one facet of humans' affective domain, which shows the compatibility of TAVI and Harmer's underlying concern about the importance of emotional engagement breathed into an effective reading.

Principle 4 appreciates providing students with appropriate hints for predicting the forthcoming in a reading text, which is an attempt to activate their schema. Goodman (1967) says, "Skill in reading involves not greater precision, but more accurate first guesses" (p.132); and Nunan (2001) in his elaboration on schematic interaction proposes, "Reading comprehension is thus an interactive process between the reader or the text, in that the reader is required to fit the clues provided in the text to his or her own background knowledge" (257). Following this Principle, the importance of guessing unknown and forthcoming to avoid incidental fragmentation (Johns \& Davis, 1983) of a reading material in TAVI, and benefiting from predicting, inferring and guessing to focus on the known information rather than unknown have been acknowledged in TAVI and confirmed by Dudley-Evans and St John (1998). These micro-reading skills are capable of providing leading preparatory and in-text activities firmly advocated in the second category of TAVI.

Meaningful connection of reading topic with appropriate related tasks during the whole process of reading and full exploitation of a reading text comprise two concluding issues addressed in Principles 5 and 6, respectively; "we need to choose good reading tasks-the right kind of questions, appropriate activities before, during and after reading, and useful study exploitation, etc." (Harmer, 2007, p.102). Following the mentioned interaction, a text should not be left like a remote island in students' mind, but it needs to be fully exploited to achieve further learning and discussion about the content and structure of it in order to "bring the text to life" (p.102). The above objectives can be realized by activities, like establishing purpose, focusing on links between function and form, transferring and extending information, guessing unknown words, applying strategies and so forth, advised in TAVI predominantly elaborated in the categories, 2,3 and 5 .

The above identified similarities connote that the chief intrinsic concerns of TAVI about the characteristics of an effective EAP reading have been orderly affirmed by Harmer's 6 Reading Principles to base an enduring analytical reference for effectiveness of a reading instruction both in the areas of ELT and EAP readings. A successful EAP reading in TAVI and general reading in Harmer's Principles confirm the decisive role of building schema, predicting, and students' maximum affective and cognitive engagement in a reading process before, during, and after a reading task.

\subsection{Procedure}

Providing a comprehensive context to search out answers for the research questions, this enquiry was conducted in four main phases,

1. Selecting representative corpus

2. Exploring stylistic patterns

3. Conducting critical analysis

4. Proposing possible solutions

To take an initial step, 30 common EAP textbooks (listed in Appendix) designed for various academic fields were randomly selected, and the organizational and stylistic structure of their reading activities were meticulously explored and recorded one by one. Then, further analysis and comparison of the identified structures yielded their dominant reading activity patterns in two groups of A and B that were rather similarly structured while the latter contained a brief pre-reading section. The characteristics of the identified structures were critically analyzed and explained based on the elaborated categories in TAVI and Harmer's (2007) Reading Principles, as outlined above. The results of the inspection were pursued by additional elaboration on the drawbacks of the present activity types and practical suggestions for their improvement. 


\section{Results}

Investigating the organizational and stylistic reading activity structure of the selected EAP textbooks published in Iran yielded two main designs. Majority of the organizations were consisted of 3 reading passages followed by a couple of activity types, whose outline illustrations (A and B) are as followings,

A:

\section{Reading Passage}

\section{Part one: Comprehension Exercises}
A: Identifying true or false statements
B: Completing the items with $a, b, c$, or $d$
$\mathrm{C}$ : Answering the questions orally

\section{Part two: Language Exercises}

A: Completing the items with $\mathrm{a}, \mathrm{b}, \mathrm{c}$, or $\mathrm{d}$

B: Filling the blanks with appropriate word form

C: Completing the passage with appropriate words

D: Putting the sentences in the right order

E: (Explaining a grammatical point) Completing the items with a, b, c, or d

\section{Reading Passage}

\section{Comprehension Exercises}

A: Identifying true or false statements

B: Writing the answer to the questions

\section{Reading Passage}

\section{Translation Exercises}
A: Translating the passage
B: Finding Persian equivalent of the listed terms

18 out of 30 studied books were designed based on the above organization including the first reading passage followed by comprehension and language activities, the second passage pursued by comprehension activities, and the third with translation activities. In this case, the principal preliminary objections are directed to the absence of pre-reading section and insufficiency of students' engagement in reading process, which could have been realized by prediction and schema building, elaborated in Discussion. Furthermore, the second observed overall design (B) is illustrated below,

B:

\section{Pre-Reading}

A: Introducing the vocabulary with their pronunciation, synonyms and one example

B: Introducing a sample grammatical point

\section{Reading Passage}

\section{Post-Reading Exercises}

\section{Part one: Comprehension Exercises}

A: Replacing the words with their synonyms

B: Matching the words with its equivalent

C: Filling the blanks with appropriate word form

\section{Part two: Language Exercises}

A: Filling the gaps with correct form of the two given verbs

B. Filling the gaps with correct form of the given verbs

\section{Reading Passage}

One part: Comprehension Exercises
A: Identifying true or false statements
B: Completing the items with a, b, c, or d

\section{Reading Passage}

\section{Translation Exercises}
A: Translating the passage
B: Finding Persian equivalent of the listed terms 
Regarding the whole corpus, 9 books out of 30 revealed Structure B consisting a pre-reading section missed in Structure A, which can be considered as an improving step although its efficiency is a matter of question explained in the coming analysis. The other parts showed more or less a similar structure to A. The remaining 3 EAP books have either no activities or few numbers of similar activities to those sketched out above. To recapitulate the above findings, Figure 1 will be helpful showing the results in a percentage analysis style.

\section{EAP Textbooks with(out) Pre-Reading Section}

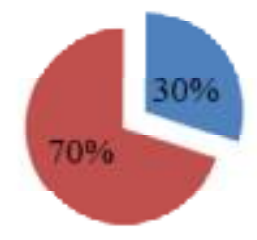

with pre-reading, $30 \%$

without pre-reading, $70 \%$

Figure $1.30 \%$ of the studied EAP textbooks contained pre-reading section and more than two third, $70 \%$, lacked the given fundamental reading phase.

Pre-reading exercises, as paramount reading activities serving the primary and curial engagement of students in a reading process and providing schema activation, have been observed only in $30 \%$ of EAP textbooks, which signifies a remarkable lack in a reading exercise design. The above illustration was presented due to the significance of pre-reading through the forthcoming analysis in Discussion affecting important components of the analytical principles.

In addition to the lack of pre-reading, as a rudimentary note of caution, it should be highlighted that the comprehension exercises demanded true/false identification, sentence completion, or oral production while there has been deployed no strategy instruction or leading clues for students to learn how to deal with them, they have been left with a passage and the questions without any sign of teacher scaffolding or even peer help. Language exercises, on the other hand, mainly focused on different forms of verbs like present, gerund or past-participle and lacked other important facets of grammatical or organizational text features, and translation part included a passage and a vocabulary equivalent finding activity as if they were only components of a successful translation. Consequently, constituents of the identified activities, i.e. comprehension, language, and translation activities did not function satisfactorily, which will be examined more critically in the following part, Discussion.

\section{Discussion}

Harmer's (2007) 6 Reading Principles aligned with five categories of TAVI have set our analytical background. The critical components are summed up as extensive reading, reader engagement, affective engagement, prediction, topictask correspondence and text full utilization, which will be the subject of exhaustive elaboration by TAVI's constituents, namely, text selection, preparatory activities, text activities, teacher-learner interaction and follow-up activities explained in detail in Methodology. The results of analyzing EAP reading activities revealed either no or partial correspondence with the given Principles as displayed in Table 1.

Table 1. Identification of Harmer's Reading Principles in Reading Exercises of EAP Textbooks

\begin{tabular}{ll}
\hline Harmer's Reading Principles & Identified Evidence \\
\hline Principle 1: extensive reading & Lack \\
Principle 2: reader engagement & Partially incorporated \\
Principle 3: affective engagement & Lack \\
Principle 4: prediction & Lack \\
Principle 5:topic-task correspondence & Partially incorporated \\
Principle 6: text utilization & Partially incorporated \\
\hline
\end{tabular}

\subsection{Lack of Principles}

Extensive reading illustrated in Table 1, as the first component of Principles and a consequence of building a self-study model in TAVI, has received the status of a lack in the activities. Encouraging students to read as much as they can is Harmer's first reading Principle while no encouragement, assistance or instruction for further reading, termed as extensive reading, was observed in EAP textbooks. Palmer was the first scholar who proposed the significance of 
extensive reading in foreign language learning as "real-world reading but for a pedagogical purpose" (Day \& Bamford, 1998, p.5). Since then numerous pedagogical benefits were cited for extensive reading; Hedge (1985) emphasized on optimizing language knowledge and motivation, Lao and Krashen (2000) reported its impact on reading fluency, and Yamashita (2013) on decreasing learner anxiety regarding affective domain, to report a few. However, EAP textbooks in Iranian universities display a certain lack in implementing this beneficial instructional practice, which could have been realized by further activities, such as introducing or specifying further similar sources, a library individual or group work or a subject-specific internet surfing.

Lack of this feature can be inferred as a gap in an effective reading process cycle because the focus of EAP textbooks is restricted to intensive time-limited classroom instruction. Even if students can establish a model for self-study encouraged in TAVI, they do not receive any hints on how to expand their EAP reading studying in case of any interest or need. Lack of organized scaffolding for further reading becomes far intense when the status of English as a foreign language is taken into consideration in the contexts like Iran, which entails subtle familiarity of students with foreign sources and highlights the role of textbook or teacher guidance.

Principle 3, "Encourage students to respond to the content of a text (and explore their feeling about it), not just concentrate on its construction" (Harmer, 2007, p.101), and TAVI's advocacy of awakening students' interest in the process of reading, particularly at preparatory level, refer to the accountability of students' affective domain since they are not objects but subjective human beings whose feelings and emotions can be a fertile field to exploit more fruitful learning. Brown (2007) writes, Carl Rogers studies human as a "primarily emotional being" (p.97) and believes, establishing interpersonal relations with learners is a necessity to facilitate learning, an educational behaviour which is called "interactional engagement" by Widdowson (1990, p.184).

While interactional engagement can be realized in varying modes, one undoubtedly can be activating students' interest and emotional sensitivity towards the subject and content of a teaching subject and a reading passage in the case of this study. Hidi (2000) claims the positive correlation of awakening learners' interest with the efficiency of cognitive functioning, and Alexander (2003) highly approves interest as one of building blocks of academic functioning while the lack of taking interest into account in EAP textbooks presupposes the learners as mechanical entities aimed to be taught without preparing their affective faculties for launching our instructional objectives. Thus, the noteworthy status of affective factors in humanistic psychology and meaningful language teaching consolidates high regard of them in Reading Principles and TAVI.

However, EAP reading exercises, as outlined in the findings, did not include even a single example of exploiting the affective determining faculty, whose deficiency seems undeniable in this regard. The identified shortcoming could have been compensated by personalizing the topic and asking for students' feeling, idea, or even personal experience in relation to the topic or some content points, for example, Are you interested in the topic of the passage? ; What is the reason of your interest or lack of it? ; How useful is this subject for you in the academic life?; Will it be useful in your future professional experience?; etc.

The other striking deficiency of the EAP reading activities is related to the lack of predicting activities concentrated upon both in Principle 4, "Prediction is a major factor in reading." and preparatory activities of TAVI. They oblige the presence of prediction and schema building in the process of reading to activate students' known information and help them to guess the unknown or build the forthcoming unknown upon the known as a meaningful enduring learning, as emphasized in TAVI. Davies and Greene (1984) conceptualize prediction as presenting a segment of a text at time and asking students to predict next events in opposition to traditional reading exercises present in their developed DART, Directed Activities Related to Text. Prediction synthesizes the reader's prior information with what comes from the text and her or his understanding for making guesses to assist the act of reading (Day \& Park, 2005).

Taking advantage of prediction strategy bears such an importance that is allocated an independent position both in Principles and TAVI while, as shown in Figure 1, approximately $70 \%$ of the EAP textbooks lacked a pre-reading section. This section could have contained some preparatory activities, like directing students towards headings, keywords, pictures, text organization, etc. to operate as schema building and prediction activities. Students' minds are not tabula rasa, but they carry background information whose activation and exploitation can help students' further cognitive and emotional engagement in the text. The skill of predicting is one of defining habits of good readers, as Duke, Pearson, Strachan and Billman (2011) writes, "Good readers frequently make predictions about what is to come" (p.56). In addition to the lack of this component in $70 \%$, the sufficiency of its presence in the remaining $30 \%$ is undoubtedly a matter of question. Regarding the activities of pre-reading section that incorporated the unfamiliar vocabulary of the text and their meaning, present in Structure B, they are solely decontextualized raw segments of meaning lacking any prediction questions. Translation of vocabulary as a pre-reading and predicting activity is one of the features of TALO, which is seriously objected by characteristics of TAVI; consequently this important higher-order reading skill (Taguchi, Gorsuch \& Sasamoto, 2006) were functionally disregarded in the design of EAP textbooks in Iran as a serious objection for validity of reading instruction via theses books.

By evidence of the above observation and inspection, 3 out of 6 Reading Principles leading to TAVI's objectives in EAP reading were not realized in the organizational and stylistic approach of the EAP reading activities. Lack of focus on extensive reading, affective engagement and prediction activities calls EAP textbooks in Iran for a fundamental revision and highlights a serious drawback in Iran's EAP literature. 


\subsection{Partial Incorporation of Principles}

Apart from the unfortunate lack of incorporating the above mentioned Principles, the rest of them are only partially present in EAP textbooks. Principle 2 emphasizing the depth of reader engagement, "Students need to be engaged with what they are reading.", Principle 5 on integrated intensive reading, "Match the task to the topic when using intensive reading texts." and Principle 6 upon optimizing text exploitation, "Good teachers exploit reading texts to the full.", are associated with intensive reading instruction and the extent of students' engagement and text utilization aimed at an effective reading instruction and performance. The evident realization of these Principles in EAP reading exercises of the studied textbooks are follow-up comprehension, language and translation activities illustrated in Structures A and B. Generally looking, comprehension exercises included some wh-questions, true/ false identification, or sentence completion by multiple options, whose goal was students' engagement in the content of a text; Language exercises were mainly related to a sentence completion by selecting or writing of the correct form of a verb or noun; and translation exercise provided a list of vocabulary and a text for translation.

The above exercise structure is notoriously in accordance with the traditional TALO style, which used to suggest some follow-up activities in the form of comprehension questions and grammar or lexis exercises, objected by TAVI. Though these activities have not completely lost the sight of Principles, they totally were ignorant of TAVI's constructive follow-up activity types, like transfer, explanation and extension of information or technique implementation, whose realization, for instance, in the form of a visual representation and recognition is one of differentiating features of good readers (Solan, Shelley-Tremblay, Hansen \& Larson, 2007). Or in the case of technique implementation, Duke and Pearson (2002) advocate the explicit description and practice of strategy use in reading to foster good reading and educate good readers. While the recognized approach on organizational and stylistic design of reading activities is called "traditional reading pedagogy" by Wallace (2001, p. 26), which disregards reading process at the expense of reading product when there is one reading passage followed by final questions, and the sight of students' preparation for delving into reading, and emotional and cognitive process between the path of reading a text to the questions are lost. The learners need to be taught how they can actively engage in the process of reading "both intellectually and emotionally" (Duke \& Pearson, 2002, p. 206).

The given gap is a grave shortcoming where the objection of the present research is settled on, when English reading skill in general and EAP reading in particular are considered as a reading process, different activities based on the suggestions of TAVI and Harmer are required. On the way of this process, to pinpoint a few, making inferences associated with proficient readers (Hammadou, 1991), the functional use of prior knowledge (Brantmeier, 2004), guessing the meaning of unfamiliar words (Dudley-Evans \& St John, 1998) and summarizing and questioning in a reciprocal teaching (Duke \& Pearson, 2002), all have been overlooked. Compromising the shortcomings, the suggested activity types could have been guessing unknown words by the help of familiar textual context instead of understanding every word, skimming for content, predicting, inferring, scanning for specific purpose, identifying main idea, establishing links between function and form accompanied by direct syntactic questions, searching for organizational pattern and identifying cohesive markers, to numerate a handful of examples; however, none of the above reading strategies, or pertinent sub-skills in another word, were observed in the reading exercises, which convincingly indicates a deficiency in EAP textbooks published in Iran.

\section{Conclusion}

In the common mainstream of EAP instruction in Iran, the majority of academic community members introduced English reading skill as a prime need supported by the present literature and the content of EAP textbooks. In spite of this priority, dealing with reading instruction and designed exercises in EAP textbooks have been predominantly confined to traditional approaches in Iran, regardless of the current advances in this field. Concerned with this inaptitude, the present research attempted to critically evaluate the dominant structure of reading activities in 30 EAP textbooks. The critical theoretical approach of the analysis was the transition of TALO to TAVI in EAP reading and Reading Principles by Jeremy Harmer (2007). They, respectively, in the areas of EAP and more overarching ELT reading advocate skill-based and functional approaches to the nurturing of reading competency and the active role of learners rather than discrete structural approach and passive learners.

The results showed that EAP reading activities have not met the requirements of TAVI and Principles 1,3 and 4 to establish extensive reading, affective engagement and prediction, and moderately considered Principles 2, 5 and 6 including reader engagement, topic-task correspondence and text utilization. In respect with fostering English reading competency, the enumerated shortcomings have culminated in grave critical deficiencies, namely lack of students' affective engagement and schema activation, notoriously upbringing dependent learners and insufficient studying habits, deprivation of the learners from peer help and collaborative working, and defects in dealing with extensive and external reading passages, to name a few prevalent consequences.

On the ground of the methodological approach of this research and illuminating findings of the analysis, we propose that TAVI has three functional phases for its comprehensive materialization,

1. Preparatory by consciousness raising on known elements

2. Exploratory by purposeful activity nomination with scaffolding

3. Didactic finalization by filling the gap between known and unknown

Concerning the optimal fulfillment of the above articulated functional scenarios, the textbooks should be successively the subject of critical review according the eclectic exploitation of the emerging approaches and methods in the domains 
of EAP, ELT and general teaching-learning cycle. Aligned with this trend, material designers and EAP textbook authors definitely need to re-evaluate their publications based on the research advances and contextual requirement, which should be followed by active editing of the instructional materials like EAP textbooks.

The proposed functional phases with a sight of required revisions in EAP textbooks published in Iran can safely benefit from TAVI's principles predominantly developed in five categories by Johns and Davies (1983), which has been outlined and detailed by some additional guidelines as following,

\section{Selection of texts}

-Selecting authentic texts on a topic-type based approach

-Selecting the text collaboratively by content and EAP teachers

-Selecting from a genre that will be encountered most frequently

-Investigating EAP students' interest and information about the text-types

\section{Preparatory activities before reading}

-Personalizing the text subject to awaken students' interest

-Activating schema by grammatical consciousness raising, structural awareness making and conceptual knowledge activation

-Making guesses about the main idea, structural design and utilized vocabulary based on peripheral clues of the main reading text

-Benefitting from micro skills like skimming to get the overall meaning in order not to break it down into unsystematic fragments

\section{The focus of reading activities}

-Inferring

-Finding key words

-Examining the graphs

-Investigating collocations

-Identifying figurative language

- Implementing strategy training

-Identifying paragraph structures

-Scanning some important details

-Searching for discourse structure

-Guessing meaning from the context

-Reading for overall meaning of the text

-Identifying main idea of each paragraph

-Conducting grammatical consciousness raising

-Predicting the following information or structure

\section{The type of teacher-learner interaction}

-Performing as a facilitating teacher rather than an instructor

-Providing opportunities for individual exploration

-Providing opportunities for peer collaboration

-Activating students' interest and engagement

-Providing guidelines for peer-assessment

-Providing guidelines for self-assessment

\section{Follow-up reading activities}

- Setting a directive ground for further study

-Teaching explicitly necessary grammatical and lexical fragments

-Implementing the actual uses of texts emphasized by the developers of TAVI,

1. Information transfer by tasks like diagramming, gapped summary, summary in the first language or target one

2. Information application by activities like analyzing data or problem solving outside or inside the classroom

3. Information extension implemented by completing the incompletely left text in the class or directing students' attention to other sources like library, books and internet to develop reference skills

4. Technique application by implementing the learned techniques on extra texts in the students' specialized field to check the transferability of them to new texts 
As a final word, if we want to articulate our prime motivation for composing this piece, it may not be inappropriate to sincerely share our sorrows with any critical reader as a colleague, editor, material designer, teacher or student. Do not you think that our inattentive performance in some cases, as academic members of different levels, ruins motivation and time of thousands of students in a country every year? Just as a simple example, if we could have textbooks based on the ongoing advances capable of engaging our students emotionally and cognitively with the reading instruction and at the end of the class it provided them with a sense of achievement, however small, how many students would leave the class with a motivating smile?

\section{References}

Alexander, P. A. (2003). The development of expertise: The journey from acclimation to proficiency. Educational Researcher, 32(8), $10-14 . \quad$ Retrieved from https://www.education.umd.edu/HDQM/labs/Alexander/ARL/Publications_files/Alexander2003.pdf

Amirian, Z., \& Tavakoli, M. (2009). Reassessing the ESP courses offered to engineering students in Iran. English for Specific Purposes World, 8(23), 1-13.

Anthony, L. (1997). Defining English for specific purposes and the role of the ESP practitioner. Retrieved from http://www.antlab.sci.waseda.ac.jp/abstracts/Aizukiyo97.pdf

Atai, M. R. (2002). ESP methodology revisited: A genre-based reading comprehension course for the students of dentistry. Indian Journal of Applied Linguistics, 28(1), 77-90.

Atefi, B. S., \& Moradian, F. F. (2013). A needs analysis of English for Specific Purposes (ESP) course for adoption of communicative language teaching: A case of Iranian first year students of educational administration. International Journal of Humanities and Social Science Invention, 2(6), 35-44.....

Brantmeier, C. (2004). Building a comprehensive theory of adult foreign language reading: A variety of variables and research methods. Southern Journal of Linguistics, 27, 1-7.

Brown, D. (2007). Principles of language learning and teaching (5 $5^{\text {th }}$ ed.). New York: Pearson Education.

Davari, H., Iranmehr, A., \& Erfani, S.M. (2013). A critical evaluation of PNU ESP textbooks. Journal of Language Teaching and Research, 4(4), 813-823. doi:10.4304/j1tr.4.4.813-823

Davies, F. (1995). Introducing reading. London: Penguin.

Davies, F., \& Greene, T. (1984). Reading for learning in the sciences. Edinburgh: Oliver and Boyd.

Day, R. R., \& Bamford, J. (1998). Extensive reading in second language classroom. New York: Cambridge University Press.

Day, R. R., \& Park, J. S. (2005). Developing reading comprehension questions. Reading in a Foreign Language, 17(1), 60-73.

Dudley-Evans, T., \& St John, M. (1998). Developments in English for specific purposes: A multi-disciplinary approach. Cambridge: Cambridge University Press.

Duke, N. K., \& Pearson, P. D. (2002). Effective practices for developing reading comprehension. In A. E. Farstrup, \& S. J. Samuels (Eds.), What research has to say about reading instruction $\left(3^{\text {rd }}\right.$ ed.) (pp. 205-242). Newark: International Reading Association.

Duke, N. K., Pearson, P. D., Strachan, S.L., \& Billman, A. K. (2011). Essential elements of fostering and teaching reading comprehension. In A. E. Farstrup, \& S. J. Samuels (Eds.), What research has to say about reading instruction ( $4^{\text {th }}$ ed.) (pp. 51-93). Newark: International Reading Association.

Goodman, K. S. (1967). Reading: A psycholinguistic guessing game. Journal of the Reading Specialist, 6(4), $126-135$. doi:10.1080/19388076709556976

Hammadou, J. (1991). Interrelationships among prior knowledge, inference, and language proficiency in foreign language reading. The Modern Language Journal, 75(1), 27-38. doi: 10.1111/j.1540-4781.1991.tb01080.x

Harmer, J. (2007). How to teach English. Essex: Pearson Longman.

Harwood, A. (2005). What do we want EAP teaching materials for? Journal of English for Academic Purposes, 4(2), 149-161. doi: 10.1016/j.jeap.2004.07.008

Hedge, T. (1985). Using readers in language teaching. Hertfordshire: Modern English Publications.

Hidi, S. (2000). An interest researcher's perspective on the effects of extrinsic and intrinsic factors on motivation. In C. Sansone, \& J. M. Harackiewicz (Eds.), intrinsic motivation: Controversies and new directions (pp. 309-339). New York: Academic Press.

Hutchinson, T., \& Waters, A. (1987). English for specific purpose: A learning centered approach. Cambridge: Cambridge University Press.

Hyland, K. (2006). English for Academic Purposes: An advanced resource book. London: Routledge. 
Johns, T., \& Davies, F. (1983). Text as a vehicle for information: The classroom use of written texts in teaching reading in a foreign language. Reading in a Foreign Language, 1(1), 1-19.

Karimkhanlouei, G. (2012). What do medical students need to learn in their English classes. Journal of Language Teaching and Research, 3(3), 571-577. doi:10.4304/j1tr.3.3.571-577

Khalili, S. M., \& Daneshvar, I. (2010). The impact of ESP materials on medical students reading proficiency. English for Specific Purposes World, 9(29), 1-12.

Krashen, S. D. (2003). Exploration in language acquisition and use. Portsmouth: Heinemann.

Lao, C. Y., \& Krashen, S. (2000). The impact of popular literature study on literacy development in EFL: More evidence for the power of reading. System, 28 (2), 261-270. doi: 10.1016/S0346-251X(00)00011-7

Mazdayasna, G., \& Tahririan, M. H. (2008). Developing a profile of the ESP needs of Iranian students: The case of students of nursing and midwifery. Journal of English for Academic Purposes, 7, 277-289.

Moslemi, F., Moinzadeh, A., \& Dabaghi, A. (2011). ESP needs analysis of Iranian MA students: A case study of the University of Isfahan. English Language Teaching, 4(4), 121-129.

Nunan, D. (2001). Second language teaching and learning. Boston: Heinle and Heinle Publishers.

Pouya, F. (2012). On the effect of translation on promoting reading comprehension in ESP. Germany: LAP Lambert Academic Publishing.

Robinson, P. (1991). ESP today: A practitioner's guide. New York: Prentice Hall.

Salehi, M. (2010). Investigating the English language needs of engineering students. English for Specific Purposes World, 10(31), 1-16.

Solan, H. A., Shelley-Tremblay, J. F., Hansen, P. C., \& Larson, S. (2007). Is there a common linkage among reading comprehension, visual attention, and magnocellular processing? Journal of Learning Disabilities, 40(3), 270-278.

Taguchi, E., Gorsuch, G. J., \& Sasamoto, E. (2006). Developing second and foreign language reading fluency and ITS effect on comprehension: A missing link. The Reading Matrix, 6(2), 1-18. Retrieved from http://www.readingmatrix.com/articles/taguchi_gorsuch_sasamoto/article.pdf

Vosoughi, M., Davoudi, Sh. E., \& Raftari, Sh. (2013). Investigating current status of English for Academic Purposes (EAP) in Iran: Revisiting ESP specificity continuum. International Journal of Applied Linguistics \& English Literature, 2(3), 54-61.

Wallace, C. (2001). Reading. In R. Carter, \& D. Nunan (Eds.), The Cambridge guide to teaching English to speakers of other languages (pp. 21-27). Cambridge: Cambridge University Press.

Widdowson, H. G. (1990). Aspects of language teaching. Oxford: Oxford University Press.

Yamashita, J. (2013). Effects of extensive reading on reading attitudes in a foreign language. Reading in a Foreign Language, 25 (2), 248-263. Retrieved from http://nflrc.hawaii.edu/rfl/October2013/articles/yamashita.pdf

Zangani, E. (2009). The ESP textbook problem: The evaluation of ESP textbooks in humanities in the undergraduate program of Iranian universities. The Asian ESP Journal, 5(2), 93-106.

\section{Appendix: The Analyzed EAP Textbooks}

1. Aaii, M. R., \& Vahid Dastjerdi, H. (2002). English for the students of theology and Islamic sciences. Tehran: SAMT.

2. Asjodi, M. (1998). English for the students of physical geography. Tehran: SAMT.

3. Azmi, M. (2001). English for the students of civil engineering. Tehran: SAMT.

4. Banieghbal, N. (1999). English for the students of library and information sciences (II). Tehran: SAMT.

5. Bidahri, P., Fallahi, M., Haghani, M., \& Maftoon, P. (2005). English for the students of engineering. Tehran: SAMT.

6. Davarpanah, H. (2005). English for the Students of Political Science. Tehran: SAMT.

7. Didari, R., \& Rakhshanfar, M. (1998). English for the Students of Rehabilitation Science. Tehran: SAMT.

8. Faghih, E. (1997). English for the students of physics. Tehran: SAMT.

9. Faghih, E., Akhavan, B., Behgam, P., \& Haghani, M. (1998). English for the students of sciences. Tehran: SAMT.

10. Farhady, H. (2001). English for the students of biology. Tehran: SAMT.

11. Hagani, M. (1998). English for Students of Power, Electronics, Control \& Communications. Tehran: SAMT.

12. Jazayeri, A. (1995). English for the Students of Food Sciences. Tehran: SAMT.

13. Karimi Doostan, Gh. (2005). English for the students of Persian literature. Tehran: SAMT.

14. Kazemi, Sh. H. (1994). English for the students of accounting and general management. Ahvaz: Islamic Azad University.

15. Khazaiefar, A., Khavari, Gh. H., \& Razai, A. A. (2000). English for the students of humanities. Tehran: SAMT. 
16. Koosha, M. (2001). English for the students of guidance and counseling. Tehran: SAMT.

17. Mahmoodi, M. A. (2001). English for students of physical education and sport science. Tehran: SAMT.

18. Mehdipoor, A. K. (2001). Advanced English for IT students. Tehran: Dibagharan.

19. Mehrabi, F. (2000). English for the students of plant protection. Tehran: SAMT.

20. Mirjalili, K., \& Roshani, M. (2005). English for the students of chemistry. Tehran: SAMT.

21. Mosalman Yazdi, H. A. (2006). Applied technical English for civil engineering. Tehran: Fadak Isatis.

22. Moshfeghi, F. (1997). English for the students of international law. Tehran: SAMT.

23. Moshfeghi, F. (1997). English for the students of social sciences (I). Tehran: SAMT.

24. Moshfeghi, F. (1998). English for the students of criminal law and criminology. Tehran: SAMT.

25. Nematollahi, V., \& Amir Hosseini, M. E. (1995). Second book on English for computer science. Tehran: Mojtamae Amuzeshi va Fanni.

26. Nikoukar, M., \& Sayehvand, Kh. (2004). English for students of mathematics. Tehran: Gostareshe Oloome Payeh.

27. Pishdad, A. (2007). English for the Students of Building Construction: Public Works. Tehran: SAMT.

28. Rezaei, J. A., \& Sadeghi, A. H. (2004). English for the students of Persian literature. Qom: Qom University Press.

29. Riazi, A. (2005). English for the students of family studies. Tehran: SAMT.

30. Shahbazi, M., \& Alidoust, E. (2008). English special text for the students of physical education and sport sciences. Tehran: Bamdad Ketab 